\title{
REMEDIOS “LA BELLA", UNA ANTIGUA DIOSA ALADA EN LA OBRA DE GARCÍA MÁRQUEZ
}

\author{
Salomé Guadalupe Ingelmo \\ (Universidad Autónoma de Madrid)
}

Entonces empezó el viento, tibio, incipiente, lleno de voces del pasado...

Gabriel García Márquez, Cien años de soledad

Entre los Inmortales, en cambio, cada acto (y cada pensamiento) es el eco de otros que en el pasado lo antecedieron, sin principio visible, o el fiel presagio de otros que en el futuro lo repetirán hasta el vértigo.

Jorge Luis Borges, El inmortal

\begin{abstract}
RESUMEN
La "Asunción" de Remedios, la bella, es sin duda uno de los episodios más fascinantes y comentados dentro de la obra de García Márquez, aunque no por ello se puede considerar de los mejor comprendidos. En el presente ensayo lo examinaremos detenidamente, centrándonos en las analogías con la tradición católica y otras religiones precedentes que en él se pueden advertir. Pues en efecto, consciente o inconscientemente, en último término, la figura de Remedios se revela heredera de un acervo ideológico y gráfico que se remonta a la Prehistoria, momento en el que surge una diosa con rasgos aviares.
\end{abstract}

\section{PALABRAS CLAVE}

Gabriel García Márquez, Cien años de soledad, Remedios la bella, Inmaculada Apocalíptica Alada, Diosa-pájaro, diosas vírgenes, tabú del incesto, redención frustrada.

\section{REMEDIOS THE BEAUTY, AN ANCIENT WINGED GODDESS IN THE LITERARY WORK OF GARCÍA MÁRQUEZ}

\begin{abstract}
Undoubtedly, the "Assumption" of Remedios the Beauty is one of the most fascinating and discussed episodes within the work of Garcia Márquez. Nevertheless it can not be considered among the best understood. In this essay we'll examine it carefully, focusing on analogies with Catholic tradition and other earlier religions that can be detected in it. Since, in fact, consciously or unconsciously, all things considered, Remedios appears as heiress of an ideological and graphic legacy that dates back to prehistoric times, when a goddess with avian traits arises.
\end{abstract}

\section{KEYWORDS}

Gabriel Garcia Márquez, One Hundred Years of Solitude, Remedios the Beauty, Apocalyptic winged Immaculate, Bird goddess, maiden goddesses, incest taboo, frustrated redemption. 


\section{Introducción}

Según el propio García Márquez, el episodio de la "Asunción” de Remedios" tiene origen en una experiencia real. Cuenta el autor que una señora cuya nieta se había fugado en la madrugada, para ocultar esta huida, decidió correr la voz de que la muchacha había ascendido al cielo. Entonces se le ocurrió que ésta sería una buena forma para hacer desaparecer a su personaje, de quien había pensado deshacerse en circunstancias mucho más vulgares. No obstante, los pormenores de la ascensión suponían un desafío.

Un día, pensando en este problema, salí al patio de mi casa. Había mucho viento. Una negra muy grande y muy bella que venía a lavar la ropa estaba tratando de tender sábanas en una cuerda. No podía, el viento se las llevaba. Entonces tuve una iluminación. "Ya está", pensé. Remedios la Bella necesitaba sábanas para subir al cielo. En este caso, las sábanas eran el elemento aportado por la realidad. Cuando volví a la máquina de escribir, Remedios la Bella subió, subió y subió sin dificultad. Y no hubo Dios que la parara. (García Márquez 1993, 26).

Aunque lo que García Márquez aparentemente contó a Vargas Llosa a propósito del proceso de redacción del episodio se diría ligeramente distinto:

La explicación de esto es mucho más simple, mucho más banal de lo que parece. Había una chica que responde exactamente a la descripción que hago de Remedios, la bella, en Cien años de soledad. Efectivamente se fugó de su casa con un hombre y la familia no quiso afrontar la vergüenza y dijo, con la misma cara de palo, que la habían visto doblando unas sábanas en el jardín y que después había subido al cielo. En el momento de escribir prefiero la versión de la familia a la real, que se fugó con un hombre, que es algo que ocurre todos los días y que no tendría ninguna gracia (Vargas Llosa 1971, 108-109).

En cualquier caso, atendiendo a las explicaciones del propio autor sobre el nacimiento de este episodio, la desaparición de Remedios ofrece el ejemplo perfecto de cómo un hecho realmente acontecido puede originar un relato mítico.

\section{Sobre la iconoclastia en la "Asunción" de remedios}

El episodio de la desaparición de Remedios a menudo se interpreta -aplicando, lo veremos más adelante, una óptica reduccionista- como una parodia de la Asunción de la Virgen María. Ernesto García Uranga (Uranga 2012, 64-66), por ejemplo, sostiene que existen varias pruebas de que nos encontramos ante un intento por desmitificar el milagro: el propio método de ascensión - pues considera las sábanas un elemento marcadamente terrenal-; la fuga real que según García Márquez inspira el relato, hecho digno de causar vergüenza y escándalo, y la burla que según él se esconde tras la afirmación "la mayoría creyó en el milagro, y hasta se encendieron velas y se rezaron novenarios", con la que se cierra la historia de Remedios. La cuestión es que Uranga atribuye este desenlace a la ingenuidad, al hábito de aceptar sin cuestionar que presuntamente se les achacaría a los creyentes en calidad de defecto. No obstante, como han puesto de manifiesto ya numerosos

\footnotetext{
${ }^{1}$ En adelante dejará de citarse el epíteto, "la bella", que acompaña a Remedios. A pesar de que otros personajes de Cien años de soledad se llaman igual, ha de entenderse por tanto que el nombre hará alusión a lo largo de todo el ensayo a este personaje concreto.
} 
estudios sobre el realismo mágico y sobre García Márquez en concreto, lo que Uranga, en una aproximación marcadamente europea, considera mera ingenuidad, responde en realidad a una idiosincrasia autóctona, a una herencia de esa América precolonial donde lo sacro y lo profano no eran opuestos sino que convivían. La literatura fantástica latinoamericana del siglo XX reclama su derecho a perpetuar ese modo sacralizado de percibir el mundo, y lo convierte en una fórmula artística que, al tiempo, defiende la singularidad patria frente a los valores europeos. Por eso en el realismo mágico lo fantástico y lo cotidiano se mezclan con esa naturalidad tan desconcertante para el lector contemporáneo. Pues con esa nueva vía de acercamiento a la realidad se está refutando que exista un único modo, el europeo, de aproximarse a la misma.

Lo que el europeo puede cometer el error de interpretar como simple irreverencia, a menudo es herencia del sincretismo que en Latinoamérica se produce entre el pensamiento religioso indígena y el impuesto por la Iglesia católica. Y por tanto esconde una carga ideológica que resulta esencial advertir si queremos realizar un análisis correcto. Conviene recordar que las religiones autóctonas no trazan una frontera entre sagrado y profano (Astvaldsson 2004, 96). Y esto se convierte en una poderosa influencia para el realismo mágico, que como manifestación literaria y artística reclama el derecho a recuperar un cierto primitivismo (Camayd-Freixas 1998), rasgo esencial del movimiento que se revela elemento identitario y sirve para reafirmar las propias raíces frente a los valores de los colonizadores europeos. El realismo mágico decide aproximarse al mundo desde una perspectiva ideológica "primitiva" y precientífica, es decir desde una óptica sacralizada frente al universo, que se considera lleno de indicios de lo sagrado. Por el mismo motivo, ante los ojos fascinados y atónitos de un hombre contemporáneo que habita un cosmos racional y secularizado, en las obras fruto de esta corriente lo maravilloso se presenta y experimenta con una naturalidad que el lector, desde su propio bagaje cultural, no logra justificar sino como un recurso literario, privándolo así de su fuerte contenido ideológico.

La propia novela asegura: "Los forasteros, por supuesto, pensaron que Remedios, la bella, había sucumbido por fin a su irrevocable destino de abeja reina, y que su familia trataba de salvar la honra con la patraña de la levitación... La mayoría creyó en el milagro; y hasta se encendieron velas y se rezaron novenarios". Es decir que son los forasteros, que en un nivel metafórico podemos identificar con los colonizadores europeos, precisamente quienes introdujeron el cristianismo en el proceso de aculturación del indígena, quienes se revelan incapaces de creer en el milagro. De donde se deduce que son ellos, y no la población local, quienes han perdido la fe en todo aquello que siguen predicando como hipócritas.

En concreto, la argumentación de Uranga parte parcialmente de un artículo de Carole Hamilton en el que la autora afirma que la interpretación del episodio como una parodia de la "Asunción" es sostenida por Humberto Robles y Roberto González Echevarría: "Humbreto R. Robles proposes that the ascent of Remedios the Beauty is a parody of the Virgin Mary's Ascension. Roberto González Echevarría comes to the same conclusion" (Hamilton 2000, 4). Pero lo cierto es que Humberto Robles únicamente indica que si de verdad existió la voluntad por parte de García Márquez de parodiar la Asunción, esto no resta ningún mérito al resultado (Robles 1993, 25). Por su parte Roberto González Echevarría, en efecto, asegura que la escena sugiere la ascensión de la Virgen; pero sin embargo no valora si hay intención irónica o no por parte del autor (González Echevarría 2011, 52).

En resumidas cuentas, la semejanza con la Asunción resulta innegable; pero ello no significa que exista necesariamente una intención iconoclasta, puesto que en ningún caso el 
episodio intenta desvirtuar la figura de la Virgen. Si bien la naturaleza lúdica que a menudo se manifiesta en el realismo mágico es rasgo distintivo ${ }^{2}$ y la carnavalización se revela una característica bastante típica del realismo mágico de García Márquez, quizá no existiese, como algunos críticos ponen de manifiesto, intención por parte del autor de aplicarla precisamente en este episodio.

Aunque en sus obras García Márquez lanza una mirada crítica que comprende la parodia sobre algunos relatos bíblicos ${ }^{3}$, no podemos interpretar el hecho como una mera censura hacia la ortodoxia católica y sus instituciones. Pues si bien ésta pueda existir a veces, observamos que el fenómeno a menudo la trasciende para abordar también, incluso más duramente, la critica a la religiosidad más popular y supersticiosa. Un ejemplo perfecto lo encontramos en su relato Un señor muy viejo con unas alas enormes, donde el pueblo, cruel y envilecido, no sale precisamente bien parado. De tal forma que la subversión de los modelos es, más que fruto de una voluntad gratuitamente transgresora contra la ortodoxia establecida, afirmación de modelos autóctonos anteriores a la colonización que corre paralela a la cristianización.

Por otro lado, si bien existen semejanzas entre el episodio de Remedios y la Asunción de la Virgen, como ilustraremos, ésta a su vez no deja de tener puntos en común con otras muchas tradiciones precedentes a la propia religión católica e incluso a la mitología grecoromana.

\section{Antecedentes iconográficos de la Asunción en el ámbito cristiano}

El modo en que Remedios asciende a los cielos, voluntariamente o no, se revela heredero de la iconografía románica, donde la ascensión del alma del difunto se representa mediante la figurita de una niña, generalmente desnuda, que es recogida en un lienzo por un par de ángeles psicopompos y elevada así hacia el cielo. No es la única fórmula, pero sí la más empleada en el ámbito funerario ("Poder y seducción”, 67). Sin embargo, cuando es la Asunción de la Virgen la que se plasma, dado que según la doctrina católica María ascendió al cielo en cuerpo y alma, a veces no es ésta sino el propio cuerpo de la Virgen -incluso amortajado según cánones bizantinos- el que asciende en un lecho de lienzos que es elevado por una pareja de ángeles (Sáenz Rodríguez y Álvarez Clavijo 1996, 411). La iconografía relativa resulta variada. Podemos encontrar a María en su lecho de muerte, rodeada por los apóstoles, mientras su alma en forma de niña es transportada al cielo por dos ángeles mediante un lienzo. Esta escena presumiblemente sigue el relato del Pseudo José de Arimatea (XI-XII; trad. De Santos 2005, 347-48), donde no se menciona la presencia de Cristo en este momento. Pero otras veces es el mismo Jesús quien lleva en brazos el alma con forma infantil, vestida con una túnica, de su madre. Esta versión de la Asunción parecería inspirarse en los textos apócrifos de San Juan Evangelista (XLIV; trad. De Santos 2005, 320) o Juan, arzobispo de Tesalónica (XII; trad. De Santos 2005, 338), en los que Jesús, acompañado de los ángeles, "después de extender sus puras manos, recibió su alma santa e inmaculada" para ponerla "en manos de Miguel, no sin antes haberla envuelto en unos como velos, cuyo resplandor es imposible describir” (Azcárate 1988, 125).

\footnotetext{
${ }^{2}$ Y herencia de la idiosincrasia indígena frente a la severidad de los colonizadores (Camayd-Freixas 1998, 73).

${ }^{3}$ En concreto, las claves bíblicas de Cien años de soledad fueron subrayadas por Ricardo Gullón (Gullón 1970).
} 


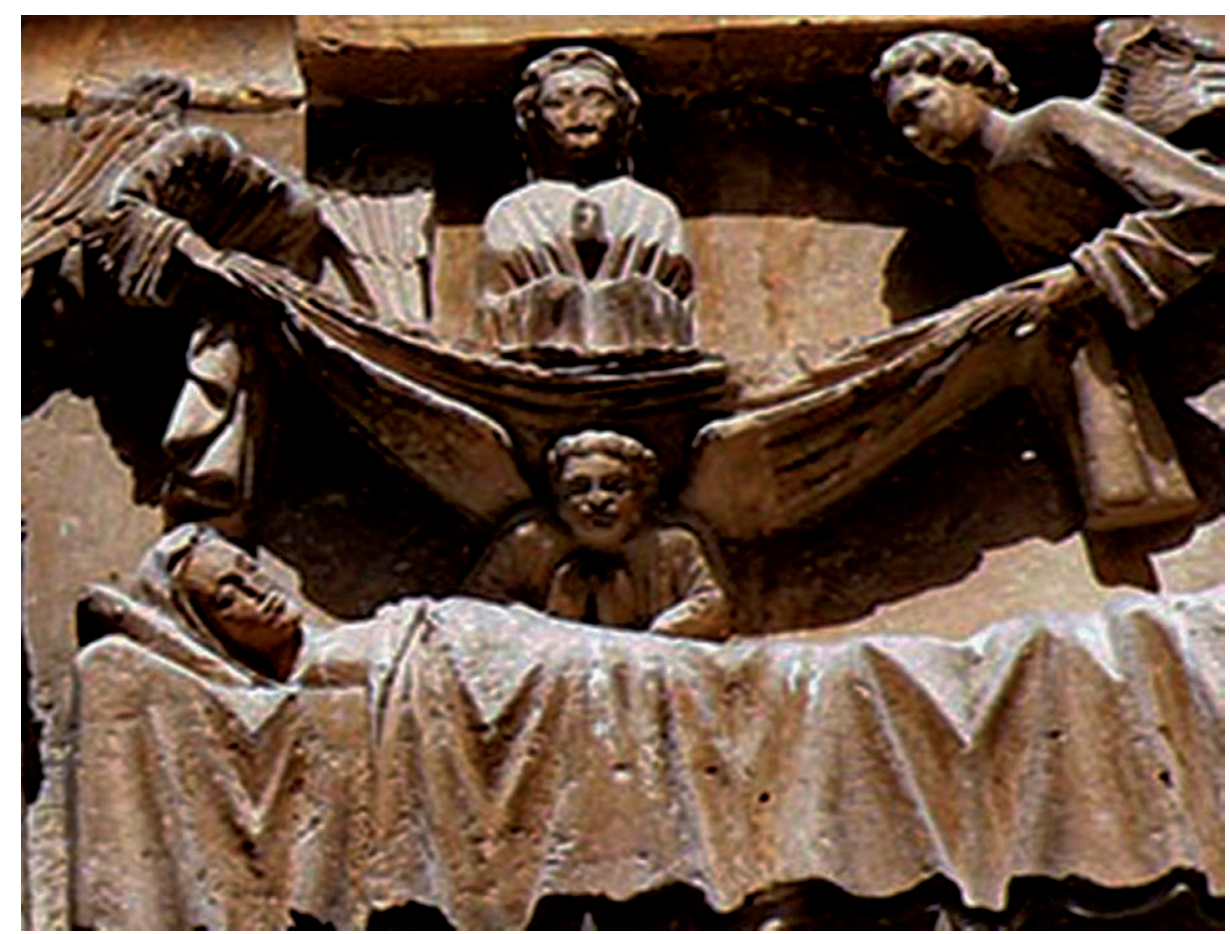

Fig. 1. Asunción de la Virgen (Siglo XIII), Catedral de la Asunción de El Burgo de Osma (Soria, España). Fotografía del autor.

La aceptación de la Asunción de María como dogma de la Iglesia católica no se produce hasta 1950, en tiempos de Pío XII. No obstante, el fervor de numerosos mariólogos hacia la Asunción parece remontarse hasta el siglo IV, y se refleja desde el siglo VI en la tradición oral y numerosos apócrifos asuncionistas, esencialmente el Tesalonicense y el Transitus $W$ (De Santos 2005, 303-351).

Pero ese vuelo místico de Remedios evoca, al tiempo, una larga tradición iconográfica en la que una diosa de especial relevancia para su panteón es representada con alas. Tradición que en efecto acabará dejando su rastro incluso en la propia imaginería católica, en las no muy conocidas vírgenes aladas.

El motivo iconográfico de las Vírgenes aladas, que no parece frecuente en España, se revela sin embargo muy común en las escuelas escultóricas hispanoamericanas de los siglos XVII y XVIII - especialmente en la quiteña del Setecientos- y pictóricas del XVI en adelante (Marrero 2008, 99-100). En ellas encontramos un gran gusto por las imágenes de la denominada Inmaculada Apocalíptica Alada, que se representa - con o sin el Niño en brazos- en actitud guerrera y a menudo pisando la cabeza de la serpiente. Esta escena, obviamente, deriva del Apocalipsis de San Juan, que curiosamente describe al personaje acompañado por signos astrales: "Una gran señal apareció en el cielo: una mujer vestida del sol, con la luna bajo sus pies y una corona de doce estrellas sobre su cabeza". En efecto, el detalle resulta interesante porque también la Inanna/Ishtar ${ }^{4}$ mesopotámica, divinidad como veremos representada con alas, tiene por atributo la estrella y muy a menudo es acompañada por la luna creciente. Inanna/Ishtar se identificó con el Lucero del alba, es decir con el planeta Venus, y aún siendo una divinidad polifacética, en ella destacan dos vertientes: la de diosa de la fertilidad y la de divinidad guerrera. En este último papel, lo analizaremos detenidamente, Inanna/Ishtar, como la mujer del Apocalipsis, se enfrenta a la serpiente o el dragón, entidad que amenaza el universo en los relatos cosmogónicos.

${ }^{4}$ Inanna para los sumerios e Ishtar para los semitas acadios. 
Dice el Apocalipsis: "El dragón comenzó a perseguir a la mujer que había dado a luz al hijo varón. Pero a la mujer le fueron dadas dos alas de águila real para que volara a su lugar en el desierto [...]. Lanzó entonces la serpiente de sus fauces un torrente de agua para ahogar en él a la mujer" (Apocalipsis 12, 13-16). Reconocemos en el fragmento a la Virgen alada, heredera de la iconografía oriental, y asistimos a su enfrentamiento con un monstruo ofídico que representa las aguas. La lucha entre el águila y la serpiente es tema antiguo en la mitología e iconografía, pues en efecto la simple observación permite constatar la enemistad natural entre los dos animales. El poema mesopotámico Etana intentó explicar esa enemistad intercalando una fábula según la cual, en el pasado, ambos seres habrían vivido juntos en un árbol. Los dos prometieron ante Shamash, dios de la justicia, que habrían velado el uno por el otro. Pero el pacto se rompería cuando, al tener progenie, el águila decidiese devorar a los pequeños de su aliado.

La lucha de la mujer alada del Apocalipsis evoca el combate entre Zeus y Tifón, que a su vez continúa una larga tradición próximo oriental -el enfrentamiento de Marduk contra Tiamat, del $\mathrm{Ba}$ al cananeo contra el dios del mar Yam...- transmitida fundamentalmente a través de Anatolia -donde encontramos el mito hitita de Hedammu o el de Ullikummi-. La visión que describe el Apocalipsis también presenta algunas semejanzas con el episodio de la mitología griega que narra cómo la serpiente Pitón persiguió encarnizadamente a Latona cuando estaba a punto de parir a Apolo. Un incidente que claramente rememora la antigua enemistad entre una divinidad femenina y un ser ofídico, discordia que más tarde sería heredada por un dios masculino.

En el Enuma Elish babilonio el protagonista de esa lucha contra el dragón es Marduk, mientras Ishtar ni siquiera se menciona como consejera del dios. Lo mismo sucede con el mito que narra la batalla entre Tishpak y el Labbu. Sin embargo, en la Mesopotamia periférica las fuentes literarias sí guardan el recuerdo de ese pasado heroico de la diosa, que quizá se atisbe también en Inanna y el Ebih, donde Inanna se enfrenta a un monte del cual salen serpientes que escupen veneno (trad. en Bottéro y Kramer 1992, 230). En el mito hitita de Hedammu (Bernabé 1987, 160-170), de origen anatolio, y en el de Ullikummi (Bernabé 1987, 178-199), de origen cananeo, Ishtar, para ayudar al dios de la tormenta Teshub, canta frente al mar con la intención de seducir al monstruo ofídico. En La lucha contra el dragón, de origen anatolio, la diosa Inara emborracha al dragón para que su amante humano pueda atarlo y el dios de la tormenta lo venza. Aunque este mito tiene una segunda versión en la cual la victoria se produce sin la ayuda de la diosa (Bernabé 1987, 33-37).

En efecto, las fuentes arqueológicas de la antigua Mesopotamia sí dejan constancia evidente del enfrentamiento entre Inanna/Ishtar y la serpiente, y de la victoria de la diosa. No es infrecuente que, en la glíptica, la divinidad se siente o se yerga sobre uno o dos dragones que le sirven de trono o de escabel según los casos, o que sujete un caduceo con dos serpientes entrelazadas. Está claro que una vez las sociedades patriarcales relegaron a estas diosas a un segundo plano, el mito de la victoria sobre el dragón y la iconografía a él vinculada pasaron a ser heredados por una divinidad masculina de carácter guerrero.

La belicosidad define también a Ishtar. Aunque en su día Amiet propuso que las alas con las que se representa a la diosa, que parecen de águila, sirviesen para subrayar su faceta astral (Amiet 1954,34), Barrelet opinaba que esos apéndices evocarían más bien su faceta guerrera, ya que el motivo del águila con las alas desplegadas, en efecto, simbolizaba precedentemente la fuerza y la victoria, por lo que en las escenas de batalla acompañaba al rey (Barrelet 1955, 236). 


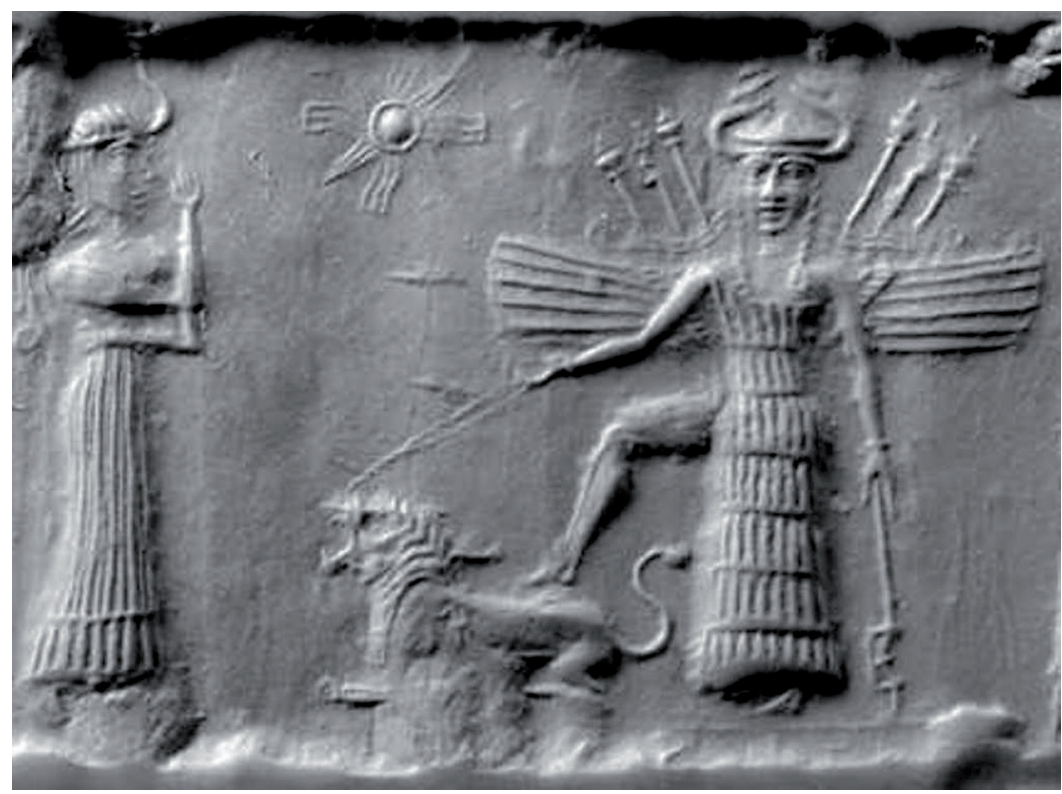

Fig. 2. Sello acadio OIM A27903 (2254-2193 a. C.). Oriental Institute, University of Chicago. <http://media. web.britannica.com/eb-media/17/24917-004-38162956.jpg>.

Precisamente en virtud de su victoria sobre el dragón, Inanna/Ishtar se habría adueñado también de algunos rasgos ofídicos, identificándose incluso con el enemigo vencido. En un himno dedicado a la diosa leemos: "como un dragón tú has depositado veneno en el país" (Hallo y van Dijk 1968, 14, línea 9). En otro himno Inanna es denominada varias veces "gran dragón” (Sjöberg, Bergmann y Gragg 1969, 29, línea 206; 36, línea 322).

Es su control sobre el dragón o serpiente, es decir sobre las aguas, el que concede a la diosa el dominio sobre la fertilidad y la abundancia, faceta que parece representarse mediante la figura de la Potnia theron o señora de las bestias. Encontramos un antecedente de esta escena tan repetida por el mundo micénico en un jarrón del siglo XXIX-XXVIII a. C. procedente de Khafajah que se conserva en el British Museum (Porada 1965, 36). La pieza, que podría ser de origen iraní, sobre un fondo repleto de animales, muestra una diosa que sujeta en cada mano una gran serpiente con cabeza leonina. En la cara opuesta se repite la misma escena, pero dos chorros de agua toman el lugar de las serpientes.

La Potnia theron o señora de las bestias, cuya condición hereda la diosa de la caza Ártemis, se vincula en la iconografía minoica y micénica a las palomas y las serpientes. De hecho no es infrecuente que las aves y las serpientes aparezcan asociadas en el Próximo Oriente, como en un altar del tercer milenio con forma de casa que fue descubierto en Ashur, en el templo de Ishtar (Andrae 1922, 36, fig. 5) o en el cilindro aparentemente para libaciones encontrado en el templo de Ashtoreth en Beth-Shan, Palestina, que combina de nuevo las palomas y las serpientes y data del siglo XII a. C. (Evans 1935, 167, fig. 129).

En realidad este culto pudo haber emigrado hasta Creta y Grecia desde Palestina, ya que en Beth-Shan aparecieron objetos minoicos y en Hazor, recipientes micénicos. De Beth-Shan procede, por ejemplo, la figurilla de una diosa desnuda de cuyos hombros se descuelga una serpiente que apoya la cabeza sobre uno de sus muslos. Así como otra de un ser con forma de serpiente y senos femeninos que sujeta ante sí un cuenco, presuntamente para recoger ofrendas de leche u otros alimentos (Cook 1930, 98).

Lo cierto es que ya en el arte prehistórico la Diosa Madre toma a veces un aspecto ofídico (Gimbutas 1989, 121-137; Johnson 1981, 121-191). En Mesopotamia, generalmente 
en tumbas, también encontramos figurillas de diosas -con o sin niño en brazos- de cabeza ofídica que datan de la primera mitad del cuarto milenio (Parrot 1981, fig. 91 y 94).

En Grecia la diosa Atenea se representará a menudo acompañada de serpientes, y de hecho las fuentes textuales parecen sugerir que se la identificó con una: según Herodoto, los atenienses estaban convencidos de que una enorme serpiente vivía en el templo y guardaba la Acrópolis, y cuando los pasteles que le ofrecían no desaparecieron en las vísperas de la batalla de Salamina, ellos interpretaron que la diosa había abandonado la ciudad (Heródoto, VIII 41).

Como García Mahíques advertía, las representaciones de la Mujer Apocalíptica vienen de muy antiguo y su origen habría que buscarlo en el arte de Oriente. Mientras, en Occidente la primera representación la encontramos en el Beato de Liebana-que ciertamente podría haberse inspirado en otro manuscrito más antiguo procedente de Siria o Egipto-, cuyas miniaturas tendrán influencia decisiva en las posteriores figuraciones sobre el Apocalipsis (García Mahíques 1995, 189).

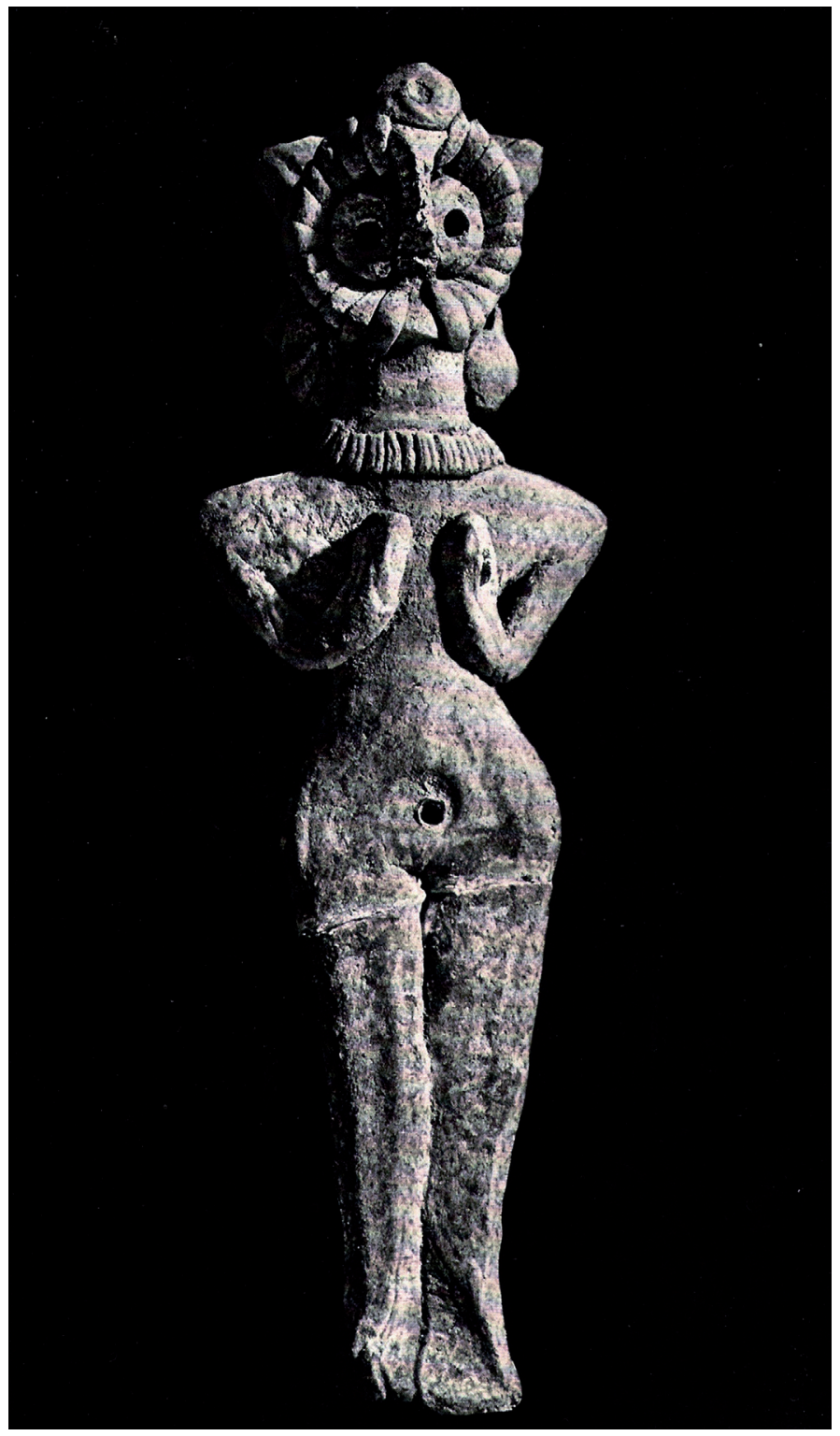

Fig. 3. Diosa con cabeza de búho (III milenio), Museo Arqueológico de Alepo. Escaneada de Parrot, A., Sumer, Madrid: Aguilar, 1981, p. 17, fig. 10. 
Ya en la Prehistoria es frecuente la representación de la Diosa Madre con rasgos típicos de búho. El búho se asocia al mundo de los muertos, pero al tiempo simboliza la maternidad porque la forma del rostro del ave evoca un útero (Johnson 1981: 47). Por eso este animal suele identificarse con la Diosa Madre (Gimbutas 1989, 190-195). Cuando en la Prehistoria la Diosa Madre toma forma de búho, normalmente se la acompaña de otros elementos que simbolizan la vida: vulvas, triángulos, serpientes, líneas en zigzag que representan el agua... Las facetas maternal e infernal, además, no son, en contra de lo que pudiera parecer, opuestas. Recordemos que en la Prehistoria la sepultura se identifica con el útero de la Diosa Madre, motivo por el cual las entradas de las tumbas megalíticas son estrechas como una vagina (Gimbutas 1989, 151-157). Parece que los seres humanos comenzaron a enterrar a sus muertos con la intención de restituirlos al vientre de la Diosa Madre, de tal forma que pudiesen renacer como hacen las semillas de los vegetales. Esto explica que a menudo las diosas de la fertilidad, que lo son también del amor, se revelen al tiempo diosas de muerte. Un ejemplo muy claro lo tenemos en la Inanna/Ishtar mesopotámica, pero también en diosas griegas más familiares como Afrodita (Graves 2002, vol. 1, 91), a la que se considera la mayor de las Parcas y hermana de las Erinias 5 , y que recibía títulos como Melenis ("la negra"), Scotia ("la oscura"), Androfonos ("la asesina de hombres") y Epitimbria ("la de las tumbas").

Esta convicción de que la Diosa Madre, a la que se identifica con la tierra, tiene la capacidad de regenerar provoca la aparición de los Dying and Rising Gods, categoría de dioses propuesta por Frazer (Frazer 1922:,338ss) que englobaría figuras cuyo ciclo vital calca el de los vegetales. En términos genéricos podemos hablar de dioses de distintas culturas próximo orientales que mueren y resucitan: Dumuzi, Oriris, $\mathrm{Ba}{ }^{`} a l$, Eshmun, Adonis, Attis, Dionisio... La muerte de estos dioses se vincula precisamente a la relación sexual mantenida con la Diosa Madre: Inanna/Ishtar hace que Dumuzi la sustituya en el infierno, Attis es víctima de los celos de Cibeles, Adonis muere mientras se lo disputan Perséfone y Afrodita, Eshmún perece por haber rechazado a Ashtarté... Las relaciones con la diosa son muy peligrosas. Por eso Gilgamesh, argumentando que todos sus amantes sufrieron destinos crueles (VI 42-79; trad. en Bottéro y Kramer 1992, 283-284), rechaza a Ishtar cuando ésta se le ofrece.

Este modelo de Diosa Madre parece producto de una mentalidad vinculada a la sexualidad masculina adolescente, esencialmente falocéntrica e inmadura. Por eso los jóvenes amantes de la diosa se exponen a la muerte y, muy a menudo, también a la castración. Esa castración física es metáfora de la castración de la personalidad, pues existe el temor a permanecer para siempre bajo la influencia femenina en la que el niño se educa hasta convertirse en hombre. Por eso, efectivamente, la Diosa Madre frecuentemente se comporta como una figura materna respecto a sus propios amantes. Por otro lado, en estos mitos, la muerte refleja la experiencia de la disolución de la personalidad que genera el orgasmo, que transporta a un estadio de preconsciencia de la masculinidad (Newmann 1973, 60-61; 158).

En las sociedades patriarcales los hombres sienten que el rol masculino podría verse amenazado por una figura femenina fuerte, de tal forma que la mujer se considera una presencia potencialmente castradora. Hasta tal punto que esa Diosa Madre, tras utilizar para sus propios fines - sexuales- a las divinidades masculinas más incautas, se nutre de ellas. La Diosa Madre, que responde al prototipo de mujer fatal o mantis religiosa y se identifica con la tierra, se regenera con la muerte en un ciclo perpetuo. El joven amante, que existe sólo en función de las necesidades de la diosa, fecunda a la Madre Tierra primero en sentido literal y, una vez cumplida su función, la hace fecunda también con su muerte: la tierra disuelve a su

\footnotetext{
${ }^{5}$ Según la Teogonía de Hesíodo, cuando Crono castra a su padre Urano, de la sangre de éste surgen los Gigantes, las Erinias y las Melias. Y de la espuma producida por los genitales amputados, Afrodita Urania
} 
progenie para obtener fertilidad y nuevo vigor. Así nace el arquetipo de la diosa de sexualidad insaciable.

A pesar del peligro que entraña para la esfera masculina, esta diosa resulta irresistible. Por eso a menudo sus amantes toman forma animal, porque aun sabiendo el riesgo al que se exponen, actúan movidos por el instinto. Así la diosa es también hechicera que convierte a los hombres en animales (Newmann 1973, 61), y que a menudo les conduce a la locura autodestructiva y castradora.

Pero volviendo a los rasgos aviares que caracterizan a determinadas diosas, hay que recordar que el ave a menudo simboliza la resurrección porque al salir de un huevo, que se diría carente de vida, parece pasar por un doble nacimiento. Además, dado que alcanzan el cielo, en muchas culturas las aves se consideran portadoras de los espíritus de los muertos. Con esta creencia ha de relacionarse la práctica de dejar que los cadáveres fuesen descarnados por aves carroñeras ${ }^{6}$ que, de esa forma, liberarían el alma de los muertos.

Esa diosa que a veces se representa con rasgos aviares y otras con rasgos ofídicos, pero que en cualquier caso es patrona de la fertilidad y también de la muerte desde el Neolítico, no aparece únicamente en ámbito semítico sino también indoeuropeo. Alberro propone que esa diosa-pájaro "pudo haberse convertido en una diosa de manantiales, ríos y otros contextos acuáticos con paralelos en las culturas de Irán e India, y en las de otros pueblos de la Antigüedad" (Alberro 2007, 7). Lo que en efecto concuerda con nuestra exposición sobre la victoria de una antigua diosa próximo oriental sobre el dragón, que le habría concedido el control sobre las aguas. No podemos evitar encontrar semejanzas con Remedios, que aúna la naturaleza de la diosa-pájaro y de la diosa-serpiente al disfrutar de largos baños y volar finalmente hacia el cielo.

José Manuel Rodríguez y Omar Salazar identificaban a Remedios con una náyade precisamente por su afición a los baños en la alberca (Rodríguezy Salazar 2010, 95). El mismo García Márquez reconocía a menudo la revelación que para él supuso el descubrimiento de los clásicos griegos, de tal forma que quizá, consciente o inconscientemente, al tiempo que evocaba imágenes propias de la tradición cristiana, podría haber tenido presente el modelo de las náyades griegas ${ }^{7}$ mientras construía el personaje de Remedios. Las ninfas y náyades son seres que, como Remedios, cautivan a los hombres. Y algunas de ellas, curiosamente, acabaron sus días en el cielo. Cinosura, ninfa del monte Ida, amamantó a Zeus cuando éste se escondía de su padre Crono, y en recompensa por ello se la colocó entre las estrellas cuando murió ${ }^{8}$. Las Pléyades, hijas del titán Atlas y la ninfa marina Pléyone y niñeras del infante Dioniso, ninfas del cortejo de Artemisa que como ella procuraban mantenerse vírgenes pero que dieron hijos a importantes dioses entre los cuales Zeus, Poseidón o Ares, fueron finalmente transformadas primero en palomas y luego en estrellas para que escapasen de la persecución de Orión ${ }^{9}$. Las narraciones en las que una joven es aceptada en el cielo ${ }^{10}$ para que se salve de la persecución de un pretendiente lascivo recuerdan el caso de Remedios.

\footnotetext{
${ }^{6}$ Atestiguada, por ejemplo, en las pinturas conservadas en Çatal Hüyük, Anatolia (6.500 a. C. - 5.700 a. C.).

${ }^{7}$ Aunque también en Latinoamérica parecen existir seres similares que podrían haberle inspirado, como las atiseinekum, una suerte de dríades colombianas, o las champallu (o zampayu), más parecidas a las náyades (Rodríguez y Rodríguez 2008, 137).

${ }^{8}$ Cinosura es también otro nombre para la constelación Osa Menor o su estrella más brillante, Polaris.

${ }^{9}$ Según otras versiones, para inmortalizarlas después de que ellas se suicidasen a causa de la pena que les causaba ver a su padre Atlas sujetando el mundo sobre los hombros.

${ }^{10} \mathrm{O}$ convertida en pájaro, como es el caso de Asteria, que se vuelve codorniz para evitar la violación de Zeus (Higinio, Fábulas 53, 1).
} 
Sin embargo, otras veces el convertirse en ave no permite salvaguardar la propia castidad. Némesis, diosa alada, perseguida por Zeus, intentó huir de éste tomando la forma de distintos monstruos y animales hasta que se transformó en una oca. Pero Zeus, convertido en cisne, consiguió unirse a ella. Némesis puso entonces un huevo que fue recogido por unos pastores y entregado a Leda para que lo cuidase. De ese huevo nacería Helena de Troya.

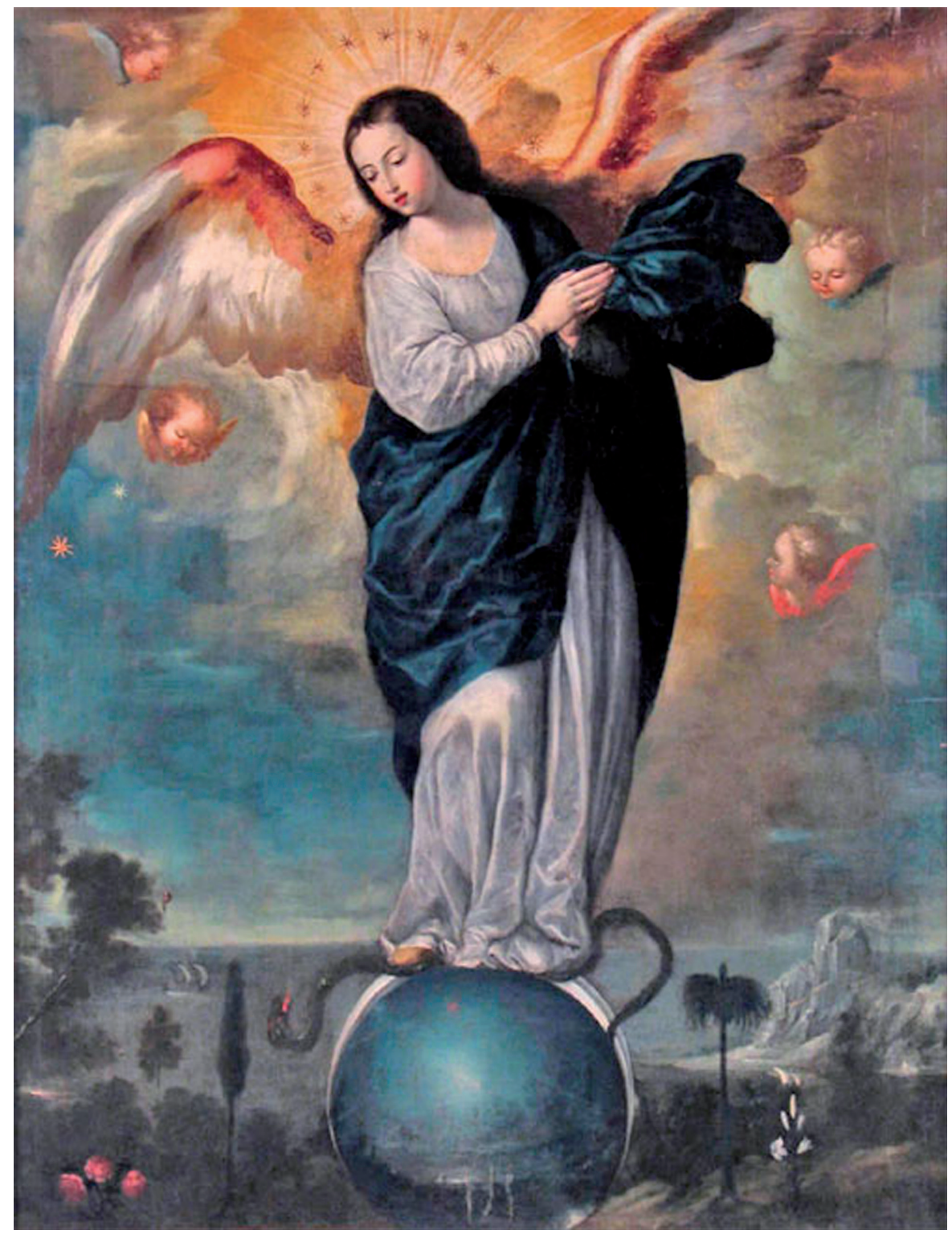

Fig. 4. Miguel de Santiago (Escuela Quiteña), Virgen alada del Apocalipsis (S. XVII). Museo del Banco Central del Ecuador. <http://es.wikipedia.org/wiki/Pintura_colonial_de_Chile\#mediaviewer/File:Virgen alada_del_Apocal\%C3\%ADpsis_Miguel_de_Santiago.jpg>.

Como observamos, la antigua diosa alada sobrevivió y pobló también la mitología e iconografía greco-romana, que influyen de forma directa en la tradición cristiana. Sirenas, Arpías y Furias perpetúan en Grecia, donde muchas aves se consideran símbolo de determinadas divinidades - la lechuza se vincula a Atenea, el cuco a Hera, la paloma a Afrodita...-, la tradición de la diosa alada que encontramos tan difundida en Mesopotamia. Allí son abundantes los sellos donde podemos admirar, en diferentes contextos, a una Ishtar 
-fácilmente identificable por los atributos que la acompañan, sobre todo leones y rosas o estrellas- dotada de un par de alas y a menudo representada en su faceta guerrera, pues de su espalda no es infrecuente que además despunten mazas. Igualmente, en Siria encontramos representaciones de Ashtarté y Anath, divinidad cazadora y señora de las bestias, con las mismas alas con las que la describen los textos ugaríticos (Cornelius 1993).

La devoción por esa diosa alada sobrevivió incluso al triunfo del cristianismo. Desde el primer cuarto del siglo XVIII, los talleres quiteños produjeron una gran cantidad de imágenes para el culto cristiano, entre las cuales la Inmaculada Apocalíptica fue una de las representaciones con mayor demanda (Pacheco 2001, 510). A esta enorme aceptación de la Virgen alada pudo contribuir la identificación con otros protectores alados precoloniales. Lo mismo había sucedido con la figura del ángel cristiano, que fue bien acogida en el mundo andino porque podía ser identificada con los Huamincas, guerreros alados, ancestros de los incas y protectores del imperio (Mujica 1996, 275). Es decir que el indio interpretaba las figuras aladas -fuesen éstas ángeles o no- como fuerzas dispensadoras de amparo.

Luego la Remedios voladora de García Márquez se podría considerar producto de una idiosincrasia patria; heredera de esa tradición de Vírgenes aladas que, curiosamente, encuentra paralelo ya en la religión y el arte de la antigua Mesopotamia.

Que la Diosa Madre se identificase con las aves desde la más remota Prehistoria no resulta tan desconcertante. Hay que tener en cuenta que para una mentalidad primitiva con un escaso conocimiento de biología, la intervención masculina en la concepción resulta difícil de comprender. En apariencia es la mujer quien se diría capaz de crear vida por sí sola. De igual forma, las aves, que originan huevos, algo que parece inerte pero de lo que sale vida, resultarían un misterio. De hecho una nueva interpretación de las Venus del Paleolítico, Neolítico y Calcolítico propone que estas figuras, tradicionalmente consideradas esteatopígicas, representasen en realidad a la Diosa Madre en su faceta de diosa-pájaro. Se sospecha ahora que su forma se debiese a que el módulo usado para su representación fuese el huevo. El tamaño desproporcionado de los glúteos se debería en realidad a la presencia en su interior del huevo cósmico. Una prueba a favor de esta hipótesis la aportaría un grabado del Magdaleniense tardío de la cueva de Fontales, en el sur de Francia, donde dentro de la silueta de una mujer de enormes posaderas descubrimos un huevo (Johnson 1981, 10-17).

Las Vírgenes aladas parecen, por tanto, sucesoras de una figura, la de la diosa-pájaro, en la que se venera la aparente capacidad femenina de generar sin intervención masculina. Lo que en efecto se ajusta perfectamente al dogma cristiano sobre la concepción sin pecado de la Virgen.

La situación cambiaría cuando el desarrollo de la ganadería ayudase a comprender la relación entre el coito y la concepción, y la intervención masculina en ésta. Entonces un dios de menor rango, hijo o hermano, pasará a convertirse en compañero de la Diosa Madre, que en origen era la única responsable de la fertilidad. En un último estadio, hacia comienzos del tercer milenio, con la constitución de estados y monarquías fuertes, las sociedades patriarcales sustituirán a la diosa, relegada a un segundo plano como hija o esposa, por divinidades masculinas marcadamente guerreras (Lerner 1990, 228-232).

\section{Remedios, heredera de las antiguas diosas del amor}

En la historia de Remedios siempre se pretende ver una inversión del sentido bíblico: frente a la ascensión de la Virgen, que concibe sin perder su pureza, la ascensión de una hembra que vuelve locos a los hombres y sobre la que los forasteros lanzan la sospecha de haber huido con un amante. 
Sin embargo, el episodio de la “Asunción” de Remedios, que pudiera parece irreverente desde la perspectiva del cristianismo, se torna lo contrario si analizado desde el punto de vista de religiones para las que la sexualidad, especialmente la sexualidad de una divinidad femenina que se convierte en patrona de la fertilidad y la abundancia, es el motor que permite el mantenimiento del orden cósmico y por tanto se estima sacra.

Las contradicciones que se advierten en Remedios, descrita como una criatura inocente pero que al tiempo vuelve locos a los hombres, a los que parece provocar e ignorar a partes iguales, son las mimas que se detectan en determinadas diosas antiguas -por ejemplo, en la Inanna/Ishtar mesopotámica-, en las que la pureza no se asocia a su sexualidad, o si lo hace es siguiendo juicios que muy poco tienen que ver con los impuestos por la moral católica.

Resulta evidente que la pureza de Ishtar no se ajusta al concepto cristiano, pues su culto comprende prácticas sexuales y en su nombre se desarrolla la prostitución sacra, actividad documentada también en Siria y Palestina y heredada por el culto griego a Afrodita. Y sin embargo sigue recibiendo el apelativo de "doncella", como entre los griegos sucede con el epíteto "Parthenos", que sobre todo se emplea con Atenea, Ártemis y Hera, aunque también se atribuye a otras divinidades como Hécate, Hebe, Perséfone o Némesis. En efecto estas diosas son doncellas o vírgenes no porque no hayan conocido varón -de hecho normalmente de su sexualidad depende la fertilidad vegetal, animal y humana-, sino porque no se unen a ninguno mediante los lazos que las instituciones prevén, es decir mediante el matrimonio. En el otro sexo encuentran sólo amantes esporádicos que, por otro lado, sufrirán un trágico fin a consecuencia de esa relación.

Sobre esa dualidad de Remedios, de pureza virginal cuando niña pero que dispersa un olor animal de hembra en celo al llegar a la pubertad, ahonda la novela: "Ursula, por su parte, le agradecía a Dios que hubiera premiado a la familia con una criatura de una pureza excepcional, pero al mismo tiempo la conturbaba su hermosura, porque le parecía una virtud contradictoria, una trampa diabólica en el centro de la candidez".

Efectivamente, como hemos visto, en varias religiones antiguas es frecuente que la Diosa atraiga a divinidades menores masculinas para asegurarse la fecundidad y también para nutrirse después de ellas. La virgen se convierte en mujer peligrosa a través de su atractivo sexual, que supone un riesgo de muerte para el hombre. En este sentido, Remedios responde a un arquetipo femenino típicamente patriarcal, producto de una sociedad que teme a la mujer.

El tabú que rodea a Remedios presenta evidentes puntos en común con mitos como el de Acteón, despedazado por sus perros. De hecho el forastero que la observa mientras se baña, casi en un calco de la tragedia de Acteón, castigado por espiar a Ártemis mientras se baña, muere al caer del tejado. Igualmente, el hombre que se atreve a jactarse de haberla manoseado durante un tumulto, muere inmediatamente con el pecho destrozado por la coz de un caballo. Y quizá no sea casual que dicho individuo profanase con su mano precisamente el vientre, un vientre destinado a ser inviolable y salvífico. De igual forma, el forastero que consigue ver el rostro de Remedios a pesar de la mantilla negra con la que ésta se cubre para asistir a misa, tras intentar conquistarla sin fortuna, debido a su obsesión, acaba descuidándose hasta parecer un mendigo y termina despedazado por un tren nocturno al quedarse dormido sobre las vías.

Las diosas vírgenes representan un modelo de mujer independiente que poco se adecúa a las sociedades patriarcales. Y que por ello, al tiempo que atrae, también repele, pues se considera amenazador para el hombre. A diferencia de las otras diosas, ellas son divinidades fuertes que no sufren las vejaciones a las que sus compañeras se ven sometidas por el sector masculino del panteón: ellas no son dominadas, raptadas o violadas, y las contadas veces que estas circunstancias pueden darse en mitos muy concretos, toman venganza contra el agresor 
con sus propias manos. A diferencia de las otras diosas, ellas no se enamoran porque ese amor las haría vulnerables y las ataría a un hogar donde se verían obligadas a desempeñar el papel femenino tradicional. Por el mismo motivo, jamás se convierten en madres. Pueden mantener relaciones esporádicas con determinados amantes o incluso revelarse muy activas sexualmente, como es el caso de la mesopotámica Inanna/Ishtar, pero el fruto no será una concepción habitual sino la perpetuación de la fecundidad del mundo.

En efecto, como estas diosas, la virgen Remedios se muestra totalmente inmune a las emociones. Ninguno de sus pretendientes logrará conquistarla. Sólo recibirán de ella indiferencia: "El día de Año Nuevo, enloquecido por los desaires de Remedios, la bella, el joven comandante de la guardia amaneció muerto de amor junto a su ventana".

Tan inmune es Remedios a las emociones humanas, que también Amaranta fracasa en su intento de emponzoñarla y perpetuar en ella su propio rencor.

Amaranta pensaba en Rebeca, porque la soledad le había seleccionado los recuerdos, y había incinerado los entorpecedores montones de basura nostálgica que la vida había acumulado en su corazón, y había purificado, magnificado y eternizado los otros, los más amargos. Por ella sabía Remedios, la bella, de la existencia de Rebeca. Cada vez que pasaban por la casa decrépita le contaba un incidente ingrato una fábula de oprobio, tratando en esa forma de que su extenuante rencor fuera compartido por la sobrina, y por consiguiente prolongado más allá de la muerte, pero no consiguió sus propósitos porque Remedios era inmune a toda clase de sentimientos apasionados, y mucho más a los ajenos.

Porque Remedios, como indica la propia novela, no era de este mundo. Es decir, no era exactamente humana o al menos no era igual que el resto de los humanos. Como veremos seguidamente, ella estaba destinada a convertirse en la madre del Salvador, aunque ese destino sea finalmente frustrado. El visionario coronel Aureliano Buendía, tan perspicaz como siempre, acierta en sus consideraciones sobre Remedios:

Parecía como si una lucidez penetrante le permitiera ver la realidad de las cosas más allá de cualquier formalismo. Ese era al menos el punto de vista del coronel Aureliano Buendía, para quien Remedios, la bella, no era en modo alguno retrasada mental, como se creía, sino todo lo contrario. "Es como si viniera de regreso de veinte años de guerra", solía decir.

Muy lejos de ser retrasada como a menudo se interpreta (Kulin 1982, 97), Remedios parece una elegida, liberada de las cadenas que normalmente atan al género femenino. Todo lo contrario de lo que entiende Carole Hamilton cuando sostiene que Remedios es la personificación del tópico de la mujer estúpida (Hamilton 2000, 5). De hecho el comportamiento de Remedios, como el de Ishtar, rompe con los moldes y no se ajusta al rol impuestos a las mujeres. Así, ante el estupor generalizado, "se vistió de hombre y se revolcó en arena para subirse en la cucaña".

Se estancó en una adolescencia magnífica, cada vez más impermeable a los formalismos, más indiferente a la malicia y la suspicacia, feliz en un mundo propio de realidades simples. No entendía por qué las mujeres se complicaban la vida con corpiños y pollerines, de modo que se cosió un balandrán de cañamazo 
que sencillamente se metía por la cabeza y resolvía sin más trámites el problema del vestir, sin quitarle la impresión de estar desnuda, que según ella entendía las cosas era la única forma decente de estar en casa. La molestaron tanto para que se cortara el cabello de lluvia que ya le daba a las pantorrillas, y para que se hiciera moños con peinetas y trenzas con lazos colorados, que simplemente se rapó la cabeza y les hizo pelucas a los santos. Lo asombroso de su instinto simplificador era que mientras más se desembarazaba de la moda buscando la comodidad, y mientras más pasaba por encima de los convencionalismos en obediencia a la espontaneidad, más perturbadora resultaba su belleza increíble y más provocador su comportamiento con los hombres.

La paradójica despreocupación de la bella Remedios -quien "se quedó vagando por el desierto de la soledad"- por su aspecto, su aparente desprecio por el cuerpo, hace que su figura nos evoque los antiguos anacoretas del primer cristianismo, aquellos que se retiraban a los desiertos de Siria y Egipto en el siglo IV, a vivir en soledad, y que también se denominan Padres del desierto.

Su aire de santidad se revela, además, de alguna forma macabra, en el aceite ambarino impregnado con su aroma que destila el cráneo roto del forastero muerto tras haberla visto bañarse, que no deja de ser una transferencia del olor que se atribuye a los restos incorruptos de los santos.

Que Remedios no ha nacido para la vida marital lo prueba la certeza de la propia Úrsula de que ningún hombre, acabada la pasión inicial, estaría dispuesto a aceptar "una negligencia que estaba más allá de toda comprensión". Y es que Remedios es la antítesis de la buena esposa y ama de casa, y carece absolutamente de adiestramiento doméstico o interés hacia las tareas femeninas.

Atribuir, por tanto, las peculiaridades de Remedios a simple minusvalía o locura (González Grau 2011; González Grau 2012) supone aplicar sobre una figura compleja un análisis reduccionista que obvia la rica herencia cultural de la que es receptora la obra y en concreto este personaje.

\section{Conclusiones sobre el valor semántico de la figura de remedios}

Como hemos visto, la "Ascensión" de Remedios, lejos de limitarse a mera subversión del dogma, se revela fruto de un fecundo legado que recibe también aportaciones de la religión nativa anterior a la colonización y paralela evangelización.

Por otro lado, la belleza de Remedios no parece argumento irrelevante. Remedios resulta inalcanzable porque, como su belleza, constituye un ideal. Igual que tantas musas, de las cuales se diría paradigma la Beatriz de Dante. Especialmente en las sociedades patriarcales, ese ideal gira entorno a la inocencia, que viene dictada por la edad y posteriormente por una puerilidad prolongada innaturalmente. La muchacha ideal está alejada del mundo, del que nada sabe. Porque cuando se convierte en una realidad alcanzable, en una verdadera mujer de vulgar carne y hueso, pierde su misterio y con ello el interés que genera. Sin embargo Remedios será salvada de ese cruel destino. A ella se le concede la inmortalidad: la posibilidad de no envejecer, de ser recordada siempre en su esplendor, joven y bella. De superar no sólo la decadencia física sino también la moral: de desaparecer antes de verse obligada a perder la ingenuidad.

Ello no obsta para que, como Camayd-Freixas pone de manifiesto, la figura de Remedios encarne también una América Latina degradada. Por eso Camayd-Freixas afirma que el episodio de la “Asunción” de Remedios encierra la clave de la percepción de Hispanoamérica 
en la novela (Camayd-Freixas 1998, 96). Y es que Remedios, la bella, Patrona de Macondo -que se identifica con toda América Latina-, al desaparecer antes de haber concebido sin mancha, como hubiese correspondido a una verdadera Virgen, posibilita el nacimiento de un falso Mesías con cola de cerdo, producto del incesto (Camayd-Freixas 1998, 271). La "Asunción" de Remedios frustra, por tanto, la inmaculada concepción que quizá habría redimido a Macondo. La maternidad de Remedios, que en efecto parece la elegida, hubiera podido lavar la mancha de pecado que acompaña a su estirpe, igual que la maternidad de María lavó el pecado del hombre. Sólo que nunca llegará a producirse.

Prueba de que es Remedios la elegida para salvar a su linaje de la endogamia y el incesto, el verdadero pecado de los Buendía, es que son precisamente los forasteros los que no pueden resistirse a su turbador olor, que sin embargo resulta imperceptible para los de la casa:

Lo que ningún miembro de la familia supo nunca, fue que los forasteros no tardaron en darse cuenta de que Remedios, la bella, soltaba un hálito de perturbación, una ráfaga de tormento, que seguía siendo perceptible varias horas después de que ella había pasado [...]. Era un rastro definido, inconfundible, que nadie de la casa podía distinguir porque estaba incorporado desde hacía mucho tiempo a los olores cotidianos, pero que los forasteros identificaban de inmediato. Por eso eran ellos los únicos que entendían que el joven comandante de la guardia se hubiera muerto de amor, y que un caballero venido de otras tierras se hubiera echado a la desesperación.

En realidad Úrsula, con su mejor intención, se equivoca al intentar apartar a Remedios de toda tentación por temor a que acabe dando a luz un monstruo con cola de cerdo. Úrsula, al lograr su propósito, priva a los Buendía de la redención y los aboca definitivamente a la destrucción. Porque, desaparecida Remedios, otra descendiente de la familia concebirá. Y al no ser ella la elegida para salvar a los suyos del destino, en efecto, dará a luz al tan temido engendro.

Al respecto cabe señalar que la teratología es una disciplina desarrollada desde la Antigüedad, generalmente vinculada a los oráculos, vaticinios y prácticas de predicción. En la antigua Mesopotamia se desarrollaron los Shumma izbu (Leichty 1970), auténticos tratados que recogen las malformaciones en los fetos humanos y animales con afán de clasificar exhaustivamente -24 tablillas con unos dos mil casos- todos los posibles fenómenos y las consecuencias en la vida pública o privada que presagiarían. Las malformaciones a menudo se han interpretado como signos de mal augurio. No es por tanto de extrañar que el nacimiento del ser deforme resulte tan temido a lo largo de toda la novela y preceda la destrucción. Esa malformación animal, la cola de cerdo, que se manifiesta en el último de los Buendía representa la degradación de la estirpe. Al tiempo que alude a cómo las bajas pasiones, en este caso las sexuales que se concretan en la atracción incestuosa, si no son controladas y reprimidas mediante normas, convierten al hombre en un animal incapaz de vivir en sociedad.

El incesto se cierne sobre los Buendía incluso cuando no lo es en sentido estricto (Levine 1971, 716). En el caso de José Arcadio y Rebeca, que en realidad es adoptada, se insinúa constantemente: cuando están haciendo el amor, él la llama "hermanita". Cuando José Arcadio le dice a Pietro Crespi, su rival, que se va a casar con Rebeca, Pietro contesta: "Es su hermana". "No me importa", replica José Arcadio. Y ante la insistencia de Pietro de que es contra natura y la ley lo prohíbe, José Arcadio zanja la discusión con un "me cago dos veces en natura". José Arcadio vivió con Rebeca creyéndola su hermana hasta 
que el padre Nicanor reveló que en realidad no existía consanguinidad entre ellos. En este caso la verdadera culpa reside en que los personajes creen estar cometiendo incesto y, aún así, persisten en violar las normas establecidas. El ejemplo contrario lo ofrece Amaranta, que no llega a consumar del todo el incesto pero que sin embargo alimenta repetidamente amores incestuosos que, al no saciarse, generan en ella una vida de frustración. Amaranta, quizá más que otros personajes, demuestra que el incesto marca como un estigma a los Buendía, determinando su destino. Por último, Aureliano Babilonia y Amaranta Úrsula, cuya relación incestuosa pone fin a la estirpe, no tienen certezas sobre la gravedad de su transgresión, pues sospechan que son hermanos y aunque el padre Nicanor les saca del error, finalmente el nacimiento de la criatura monstruosa les descubre que en realidad eran tía y sobrino.

Las relaciones familiares de los Buendía resultan tan intrincadas y tortuosas, tan trufadas de transgresiones, tan perversas y pervertidas incluso, que a menudo ni ellos mismos pueden estar seguros de la naturaleza de los lazos que les unen. Una incertidumbre que es alimentada también en el lector mediante la constante repetición de nombres a lo largo de distintas generaciones. De alguna forma, el que de hecho los orígenes de la estirpe no estén en el incesto, pues los bisabuelos de los fundadores José Arcadio y Úrsula no son familia sino socios, viene a confirmar la progresiva degradación de la misma, que ha perseverado por propia voluntad y soberbia, no por disposición genética, en sus malos hábitos.

En cualquier caso, cabe recalcar que en algunas sociedades el concepto de familia, y por tanto de incesto, es mucho más amplio y no se circunscribe a los lazos de sangre. Como Urbina Joiro recuerda, antropólogos como James Frazer pusieron de manifiesto esta realidad a principios del siglo XX, demostrando que la prohibición del incesto es más fuerte entre clanes matriarcales, a los que pertenece el de los Buendía. En estos clanes se pueden considerar parientes a individuos de familias ajenas que toman por propio un clan, como ocurre con Rebeca, adoptada por Úrsula y José Arcadio (Urbina Joiro 2008, 137).

El incesto no ha de entenderse únicamente como un tabú ligado a la moral sexual o impuesto por la salud genética. El incesto implica la trasgresión de las normas sociales, la ruptura de pactos, y por tanto pone en peligro la estabilidad de la comunidad. Por otro lado, en Cien años de soledad se asocia la exogamia al progreso. En efecto las sociedades más abiertas a las influencias exteriores, las que demuestran su capacidad de tolerancia y sincretismo, son las que más y más rápidamente logran evolucionar. En el extremo contrario encontramos sociedades endogámicas y cerradas como la de Macondo, que constantemente se describe como un lugar alejado del resto del mundo y sus noticias. Recordemos que José Arcadio, por sus propios medios, sin estar al corriente de una teoría comprobada siglos antes pero desconocida en Macondo, deduce que la Tierra es redonda como una naranja. Y su esposa Úrsula, por ello, lo toma por loco. "En el mundo están ocurriendo cosas increíbles", le decía José Arcadio a Ursula. "Ahí mismo, al otro lado del río, hay toda clase de aparatos mágicos, mientras nosotros seguimos viviendo como los burros". En efecto José Arcadio, el único visionario dispuesto a recoger el testigo de Melquíades ${ }^{11}$, es considerado un perturbado y acaba sus días atado a un árbol.

No hay progreso en Macondo porque allí se practica el incesto de las ideas, porque no hay exogamia intelectual (Camayd-Freixas 1998, 276). Y por lo tanto su historia no es

\footnotetext{
${ }^{11}$ Paradigma del dios o héroe civilizador que encuentra ejemplo en las más diversas culturas: Enki en Mesopotamia, Osiris en Egipto, Prometeo en Grecia, Odín en el ámbito nórdico, Bochica en Colombia, Quetzalcóatl en México, Viracocha en Perú...
} 
lineal sino circular, cerrada sobre sí misma. Incapaz de aprender de sus errores, destinada a consumirse estérilmente y repetirse una y otra vez. La imagen evoca, como tantas veces se ha manifestado, un tiempo mítico y no histórico. Pero también evoca, a la vez, una imagen desencantada de una Latinoamérica subdesarrollada que persiste en sus faltas, vicios y lacras. Por tanto en Cien años de soledad el incesto es, al tiempo, alegoría de anquilosamiento intelectual, de retraso y aislamiento. Circunstancias que llevan a sus protagonistas, a Latinoamérica, a la soledad y el olvido.

Y sin embargo, contemporáneamente, Cien años de soledad previene contra la adopción de valores foráneos y ajenos a la comunidad, contra la prostitución de los propios principios, que también conduce a la destrucción a través de la pérdida de identidad. Así Macondo, que escoge el auge fácil de la Compañía Bananera aunque el precio consista en seguir siendo parte de un sistema neocolonial, entra en decadencia tras la fuga de los inversores extranjeros y acaba arrasada. Se deduce que, para tener un futuro, Latinoamérica ha de aprender a encontrar su propio camino, labrado en el respeto de sus antiguas raíces y de la idiosincrasia nacional, pero al tiempo abierto a influencias externas positivas sin que ello signifique dejarse colonizar por ideas que le son extrañas.

De alguna forma, la Latinoamérica de la novela escoge su sino cuando da de lado a la recién coronada Remedios -significativamente, "la única que permaneció inmune a la peste del banano"- como reina del carnaval y proclama en su lugar a la forastera Fernanda del Carpio, que encarna todos los vicios del continente. Hija de familia noble pero empobrecida, Fernanda es una cachaca procedente del interior del país, y por ello representa una mentalidad más cerrada e inmovilista, obstinada en sus decadentes tradiciones: caprichosa, con ínfulas de grandeza y un apolillado concepto sobre los estamentos sociales, fanática religiosa, déspota, neurótica, egoísta e insensible incluso con su propia hija. Su imperio marca la definitiva e irreversible decadencia de los Buendía, pues es ella quien destruye los últimos puentes que existen entre la familia y el mundo, convirtiendo la casa en un adusto y oscuro panteón.

Remedios, entronizada igual que una Virgen, es brevemente adorada y llevada en procesión cuando se la elige reina del carnaval, fiesta pagana que, como las bacanales dionisiacas, evoca cultos a la fertilidad. Pero el sino de los Buendía no se puede esquivar, y Remedios, si bien perseguida por la amenaza de la maternidad, ese peligro que Úrsula intenta eludir noche y día, jamás llegará a dar a luz al Salvador. Porque su estirpe está condenada a extinguirse. Por ese motivo todo parece conjurarse en contra de esa concepción: el caso más sobrecogedor es el de los diecisiete Aurelianos llegados a la ciudad y contra los cuales Úrsula previene a Remedios -“Abre bien los ojos. Con cualquiera de ellos, los hijos te saldrán con cola de puerco"-, exterminados en una sola noche como por obra de una mano ineludible. La misma que no tiembla al firmar la sentencia de muerte de los Buendía. Porque las estirpes condenadas a cien años de soledad no tienen una segunda oportunidad sobre la tierra.

\section{REFERENCIAS}

ALBERRO, M.

2007 “La Diosa-Pájaro del Neolítico y su posible continuación en las diosas de manantiales y ríos de los celtas y otros pueblos indoeuropeos", Habis 38, pp. 7-30.

AMIET, P.

1954 "Problèmes d'iconographie mésopotamienne II", Revue d'Assyriologie 48, pp. 32-66. 
ANDRAE, W.

1922 Die archaischen Ishtar-Temple in Assur, Wissenschaftliche Veröffentlichung der Deutschen Orient $\square$ Gesellschaft 39, Leipzig: J. C. Hinrichs.

ASTVALDSSON, A.

2004 "El flujo de la vida humana: el significado del término/concepto de huaca en los Andes", Hueso húmero 44, pp. 87 - 110.

AZCÁRATE DE LUXÁN, M.

1988 "El Tránsito de la Virgen a través del arte", Cuadernos de arte e iconografía I. 1, pp. 121-134.

BARRELET, M.-Th.

1955 “Les déesses armées et ailées”, Syria 32, pp. 222-260.

BERNABÉ, A.

1987Textos literarios hetitas, Madrid: Alianza Editorial

BOTTÉRO, J. - KRAMER S. N.

1992 Uomini e dei della Mesopotamia, Turín: Einaudi.

CAMAYD-FREIXAS, E.

1998 Realismo mágico y primitivismo: Relecturas de Carpentier, Asturias, Rulfo y García Márquez, Lanham (Maryland): University Press of America.

\section{COOK, S.}

1930 The religion of ancient Palestine in the second millennium B.C., in the light of archoology and the inscriptions, The Schweich Lectures of the British Academy 1925, Londres: British Academy.

CORNELIUS, I.

1993 "Anat and Qudshu as the «mistress of animals». Aspects of the Iconography of the Canaanite Goddesses”, Studi epigrafici e linguistici sul Vicino Oriente Antico 10, pp. 21-45.

EVANS, A.

1935 The palace of Minos at Knossos. (vol. 1-4), Londres: Macmillan.

FRAZER, J. G.

1922 The Golden Bough: A Study in Magic and Religion, Londres: The Macmillan Company.

GARCÍA MAHÍQUES, R.

1995 “Perfiles iconográficos de la Mujer del Apocalipsis como símbolo mariano (I): Sicut mulier amicta sole et luna sub pedibus Rius", Ars longa: cuadernos de arte 6, pp. 187-197.

GARCÍA MÁRQUEZ, G.

1993 El olor de la guayaba: Conversaciones con Plinio Apuleyo Mendoza, Buenos Aires: Editorial Sudamericana. Tercera edición. 
GARCÍA URANGA, E.

2012 Desmitificación de dogmas y devociones Católicas en "Cien años de soledad", Bloomington: Palibrio.

GIMBUTAS, M.

1989 The language of the goddess, San Francisco: Harper and Row.

GONZÁLEZ ECHEVARRÍA, R.

2011 Mito y archivo. Una teoría de la narrativa latinoamericana, México D. F.: Fondo de Cultura Económica.

GONZÁLEZ GRAU, Á.

2011 "Trastornos del estado de ánimo en cien años de soledad. Ilustración mediante un caso clínico", Revista Medicina 33/2, pp. 115-129.

2012 Los locos de Macondo. Trastornos mentales en Cien años de soledad. EBook Kindle.

GRAVES, R.

2002 Los mitos griegos (2 vols.), Madrid: Alianza Editorial.

GULLÓN, R.

1970 García Márquez o el arte de contar, Madrid: Taurus.

HALLO, W. - VAN DIJK, J.

1968 The Exaltation of Inanna, New Haven: Yale University Press.

HAMILTON, C.

2000 "Overview of «One Hundred Years of Solitude»". Literature of Developing Nations for Students: Presenting Analysis, Context, and Criticism on Literature of Developing Nations, Elizabeth Bellalouna, Michael L. LaBlanc, e Ira Mark Milne (ed.), Vol. 2, Detroit: The Gale Group, Literature Resource Center. Web. <http://history.farmlib.org/pdfs/One Hundred_Years_of_solitude.pdf $>$.

JOHNSON, B.

1981 Lady of the Beasts: Ancient Images of the Goddess and Her Sacred Animals, San Francisco: Harper \& Row.

KULIN, K.

1982 "Mito y realidad en «Cien años de soledad» de Gabriel García Márquez", Actas del IV Congreso de la Asociación Internacional de Hispanistas (Salamanca, agosto de 1971), Eugenio de Bustos Tovar (ed.), Salamanca: Universidad de Salamanca, pp. 91-100.

LEICHTY, E.

1970 The Omen series “šumma izbu”, Locust Valley: J. J. Augustin.

LERNER, G.

1990 La creación del patriarcado, Barcelona: Editorial Crítica. 
LEVINE, S. J.

1971 "La maldición del incesto en Cien años de Soledad", Revista Iberoamericana 37.76, pp. 711-724.

\section{MARRERO ALBERTO, A.}

2008 "Un cuadro de la Inmaculada alada en Santa Catalina de Tacoronte", Revista de historia canaria 190, pp. 99-110.

MUJICA, R.

1996 Ángeles apócrifos en la América Virreinal, Lima: Fondo de Cultura Económica. Segunda edición corregida y ampliada.

NEWMANN, E.

1973 The Origins and History of Consciousness, Princeton: Princeton University Press.

\section{PACHECO BUSTILLOS, A.}

2001 "La virgen apocalíptica en la Real Audiencia de Quito: aproximación a un estudio iconográfico", Actas III Congreso Internacional del Barroco Americano: Territorio, Arte, Espacio y Sociedad (Universidad Pablo de Olavide, Sevilla, 8 al 12 de octubre de 2001), Sevilla: Universidad Pablo de Olavide, pp. 504-520.

PARROT, A.

1981 Sumer, Madrid: Aguilar.

PORADA, E.

1965 The Art of Ancient Iran: Pre-Islamic Cultures, New York: Crown.

ROBLES, H.

1993 "El primer viaje alrededor del mundo: de Pigafetta a García Márquez", Kipus: revista andina de letras 1/II, pp. 5-26.

RODRÍGUEZ, M. - RODRÍGUEZ J. M.

2008 "El delirio que viene de las ninfas en la novela latinoamericana: «nada más que ser feliz», Revista chilena de literatura 73, pp. 189-215.

RODRÍGUEZ, J. M. - SALAZAR, O.

2010 “Las ninfas en Cien años de soledad”, Atenea 501, pp. 95-112.

SÁENZ RODRÍGUEZ, M. - ÁLVAREZ CLAVIJO, Mª T.

1996 "Los temas iconográficos de la Anunciación-Coronación y de la Asunción en la escultura de los siglos XII-XIII en La Rioja, y sus relaciones con Álava". Cuadernos de sección. Artes plásticas y monumentales Donostia 15, pp. 405-421.

SANTOS OTERO, A. de (ed.).

2005 Los evangelios apócrifos, Estudios introductorios y versión de los textos originales, Madrid: Biblioteca de autores cristianos. Cuarta impresión. 
SJÖBERG, A. - BERGMANN, E. - GRAGG, G. B. (eds.).

1969 The Collection of the Sumerian Temple Hymns. Texts from Cuneiform Sources 3, Locust Valley: J. J. Augustin.

URBINA JOIRO, $\mathrm{H}$.

2008 "El amor en los tiempos de «Cien Años»", Revista Colombiana de Reumatología 15/3, pp. 137-138.

VARGAS LLOSA, M.

1971 García Márquez: historia de un deicidio, Barcelona: Barral Editores.

VV. AA.

2006 Poder y seducción de la imagen románica, Aguilar de Campoo (Palencia): Fundación Santa María la Real. 